\title{
QUENCHING-INDEPENDENT MEASUREMENT OF SPECIES CONCENTRATIONS IN FLAMES BY LASER-INDUCED FLUORESCENCE
}

Final Report

January 1, 1988 - December 31, 1989
Rempol bu

OCT O 51990

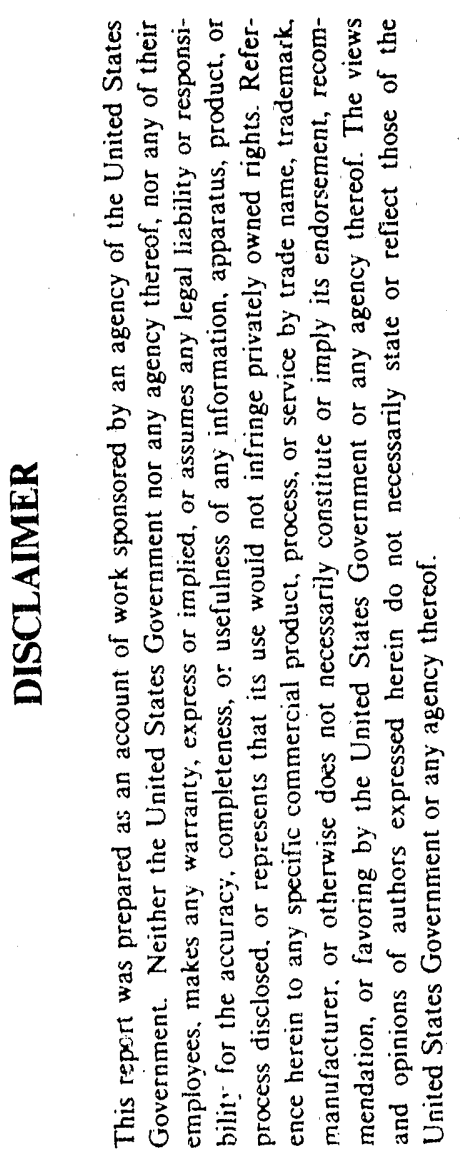

\author{
J. Thaddeus Salmon \\ Campbell D. Carter \\ Normand M. Laurendeau
}

Flame Diagnostics Laboratory

School of Mechanical Engineering

Purdue University

West Lafayette, Indiana 47907

September, 1990

Prepared for

THE UNITED STATES DEPARTMENT OF ENERGY AGREEMENT NO. DE-FG()2-88ER 13866 


\begin{abstract}
This report describes work accomplished in the last two years on measurement of species concentrations in flames via laser-induced fluorescence. During this period, we have published absolute number densities of atomic hydrogen in subatmospheric, premixed $\mathrm{C}_{2} \mathrm{H}_{4} / \mathrm{O}_{2} / \mathrm{Ar}$ flames at equivalence ratios of 1.0 and 1.7 via two-photon excited fluorescence. This work has led to the development of a new single-laser, two-step fluorescence method for the detection of atomic hydrogen in flames. Using photoionization controlled.loss spectroscopy (PICLS), we have verified the $\mathrm{T}^{-1 / 2}$ dependence of quenching on temperature for atomic hydrogen, in agreement with kinetic theory. Previous work on pyrometry using laser-saturated fluorescene (LSF) and the anomalous fluorescence from pyrene has evolved into publication of a major review paper on temperature measurements by light-scattering methods. Finally, we have demonstrated the feasibility of quantitative LSF measurements of NO concentration by obtaining relative saturation curves and NO fluorescence profiles.
\end{abstract}

\title{
NOTICE
}

This report was prepared as an account of work sponsored by the United States Government. Neither the United States nor the Department of Energy, nor any of their employees, nor any of their contractors, subcontractors, or their employees, makes any warranty, express of implied, or assumes any legal liability or responsibility for the accuracy, completeness, or usefulness of any information, apparatus, product or process disclosed or represents that its use would not infringe privately-owned rights. 


\section{INTRODUCTION}

The primary goal of this research has been to develop quantitative laser fluorescence methods for measuring the concentrations of intermediate species that are important in the chemistry of flames. The accuracy of the Huorescence techniques can be assessed through comparison with independent diagnostic methods. The applicability of the techniques over a range of flame conditions can be evaluated by performing the fluorescence experiments in a flat flame burner operated at a variety of flame pressures, temperatures and equivalence ratios.

In previous DOE-supported work, we have demonstrated quantitative laser-saturated fluorescence (LSF) measurements of $\mathrm{OH}$ concentration in (1) premixed hydrogen and hydrocarbon flames over wide ranges of fiame pressure and stoichiometry [1-4] and (2) nonpremixed hydrogen flames at 1 atm under both laminar and turbulent conditions $[5,6]$. We have also conducted LSF measurements of NH [7], demonstrated measurements of atomic hydrogen via two-photon excitation [8], and developed a technique for measuring the concentrations of polycyclic aromatic hydrocarbons in vaporous mixtures [9]. More recently, we have developed a quenching-independent method $[10,11]$ of measuring atomic hydrogen via two-photon excitation called photoionization controlled-loss spectroscopy (PICLS) and demonstrated a single-laser thermometric technique using the so-called anomalous or dual fluorescence of molecular pyrene [12,13]. Over the current period of the grant we have (1) measured absolute number densities of atomic hydrogen in hydrocarbon flames via two-photon excited fluorescence, (2) developed a new single-laser, two-step method for fluorescence detection of atomic hydrogen in flames, (3) employed PICLS to establish that quenching of atomic hydrogen is consistent with kinetic theory, (4) published a major review of lightscattering methods for temperature measurements, and (5) demonstrated the feasibility of NO concentration measurements via laser-saturated fluorescence (LSF). 


\section{RESEARCH PROGRESS}

\section{Atomic Hydrogen Measurements in Hydrociarbon Flames}

In previous work [10], we have compared conventional fluorescence measurements of atomic hydrogen, which assume a constant rate coefficient for quenching, to measurements using photoionization controlled-loss spectroscopy (PICLS), which are independent of quenching, in $\mathrm{H}_{2} / \mathrm{O}_{2} / \mathrm{N}_{2}$ flames at 20 Torr. This comparison demonstrated the need to account for quenching in the preheat zone when using conventional Huorescence. However, further studies showed that at higher pressures (72 Torr), conventional Huorescence measurements and PICLS measurements agreed very well, except below $2 \mathrm{~mm}$ above the burner surface; hence, in such flames, the rate coefficient for quenching can be assumed to be nearly constant [11]. Thus, in this study [14], conventional two-photon measurements are calibrated in the post-flame zone of a premixed hydrocarbon flame by essentially presuming partial eọuilibrium.

Our experiments, shown in Fig. 1, use a dye laser (Molectron DL-18) pumped by a frequency-doubled, Q-switched Nd:YAG laser (Molectron MY-34) to deliver nanosecond pulses of tuned radiation into flat premixed flames. The dye is Fluorescein-548 in a basic $(\mathrm{NaOH})$ solution of methanol. The frequency-doubled output from the dye laser, at a wavelength of $275 \mathrm{~nm}$, is focused into a Raman cell having a length of $1 \mathrm{~m}$ and filled with hydrogen at a pressure of $850 \mathrm{kPa}$. The output from the Raman cell is dispersed by a Pellin-Broca prism, and the third anti-Stokes component $(205 \mathrm{~nm})$ is directed over the center of a sintered-bronze flatflame burner having a diameter of $6 \mathrm{~cm}$. The pulse energy of the $205 \mathrm{~nm}$ beam is $55 \mu \mathrm{J}$, and the linewidth (FWHM) is $2.0 \mathrm{~cm}^{-1}$. The $205-\mathrm{nm}$ beam excites atomic hydrogen from the ground state $(n=1)$ to the second excited state $(n=3)$ via a two-photon transition.

Fluorescence from the directly excited state to the first excited state $(n=2)$ at $656 \mathrm{~nm}$ is isolated by a Spex $3 / 4$ meter spectromcter. The cutput from the exit slit is monitored with a 


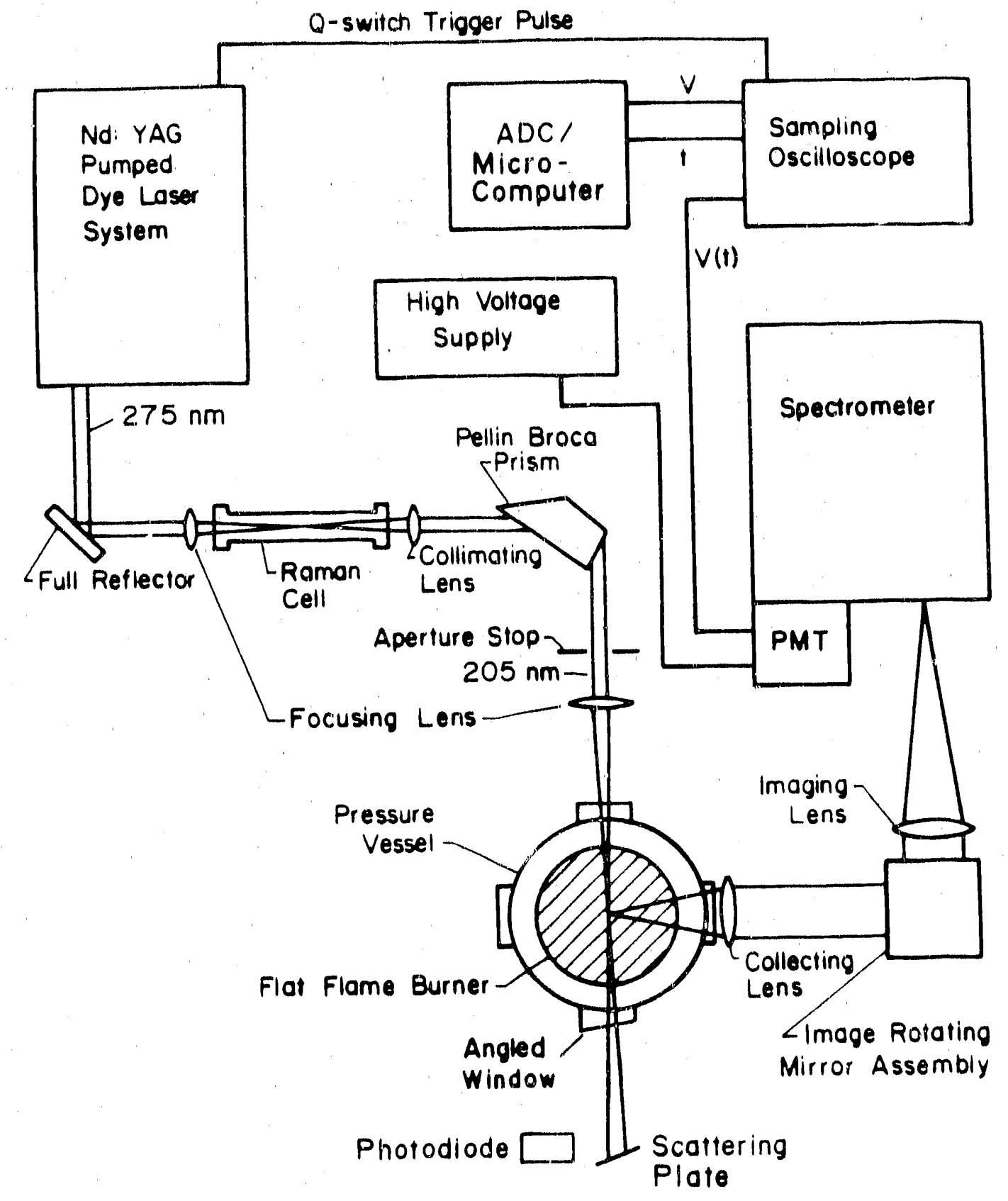

Fig. 1. Experimental apparatus for two-photon fluorescence measurements of atomic hydrogen. 
specially wired Hamamatsu R-955 photomultiplier tube [14], and the output is sent to a Tektronix 5S14N sampling module. The sampling window is set at the temporal peak of the fluorescence pulse. The peak fluorescence signal is digitized and stored by a microcomputer. The instantaneous power of the laser beam is monitored with a UV-sensitive silicon PIN photodiode; the output from the photodiode is sent to a second sampling module (Tektronix 7S14). This output also is digitized and stored by the microcomputer.

Fluorescence is collected at a right angle to the axis of the laser beam with the entrance slit opened to accept the entire width of the fluorescence volume. For two-photon absorption, the ground state population is equivalent to $\mathrm{N}_{\mathrm{T}}$, the total inirial population of atomic hydrogen. Thus, $\mathrm{N}_{\mathrm{T}}=C \mathrm{CV}_{\mathrm{f}} / \mathrm{V}_{\mathrm{L}}^{3 / 2} \mathrm{~T}^{1 / 2}$ where $\mathrm{V}_{\mathrm{f}}$ is the observed fluorescence voltage, $\mathrm{V}_{\mathrm{L}}$ is the measured laser voltage, $T$ is the flame temperature, and $C$ is the calibration factor for the experimental system [14]. The $\mathrm{V}_{L}^{3 / 2}$ dependence reflects the experimentally measured functional relationship between fluorescence intensity and laser power, while the $T^{1 / 2}$ dependence reflects the influence of collisional effects on fluorescence quenching when the effective cross-section is independent of both stoichiometry and temperature (see Section 3). The calibration factor can be found by applying the previous equation at a point where $N_{T}$ is known and where $V_{f}, V_{L}$, and $T$ are measured.

Once the system is calibrated at one point, the number density at any other location and in any other flame can be obtained from a fluorescence measurement and a temperature measurement. At each point measurements of $V_{f}$ and $V_{L}$ were averaged over 600 laser shots. Quantitative fluorescence measurements were obtained by (1) measuring the $\mathrm{OH}$ concentration and flame temperature in the post-flame zone, and (2) determining the concentration of atomic hydrogen by assuming partial equilibrium. The equations for partial equilibrium include four equilibrium constant $\left(K_{p}\right)$ expressions and four atom-balance expressions for hydrogen, carbon, oxygen, and argon [14]. For closure, the mole fraction of $\mathrm{OH}$ is obtained from laser-saturated fluorescence measurements calibrated by absorption [2]. The temperature, required for the 
equilibrium constants, is measured with miniature $\mathrm{Pt} / \mathrm{Pt}-10 \% \mathrm{Rh}$ thermocouples that were silicacoated and corrected for radiation loss.

A comparison of fluorescence measurements of atomic hydrogen and predictions from partial-equilibrium calculations is shown in Fig. 2 for the fuel-rich $(\Phi=1.7)$ flame at 72 Torr. Also shown are profiles of the flame temperature and the number density of $\mathrm{OH}$ that were used in the partial-equilibrium calculations. The $\mathrm{H}$-atom measurements are calibrated by partial equilibrium at a height of $50 \mathrm{~mm}$ above the burner. Although the fluorescence measurements are corrected for quenching by dividing by $\mathrm{T}^{1 / 2}$, the temperature profile yields a maximum correction of about $3 \%$. Figure 2 also indicates that partial equilibrium is valid at heights greater than $20 \mathrm{~mm}$ from the burner and begins to break down below this height. The breakdown results in a a underprediction of the number density of atomic hydrogen as the reaction zone is approached, which is the same trend as that found in previous hydrogen flames [11]. The relative peak heights of the hydrogen atom and $\mathrm{OH}$ number densities are approximately 13:1 compared to $4: 1$ for the stoichiometric flame.

Because variations in quenching have been accounted for by using a temperature dependence in the number density calculations, the calibration factors for the stoichiometric and fuel-rich flames should be equal to within the uncertainty of the calibration. The calibration factor for the fuel-rich flame, however, is about $27 \%$ higher than that for the stoichiometric flame. Moreover, the accuracy of the number densities is $40 \%$ for the stoichiometric flame and $15 \%$ for the fuelrich flame. The lack of accuracy in the stoichiometric flame is caused by an increased sensitivity of the partial-equilibrium calculations to uncertainties in both the equivalence ratio and the measured $\mathrm{OH}$ concentration. Slightly rich flames appear to be the best candidates for calibrating measurements tomic hydrogen by partial equilibrium [14]. 


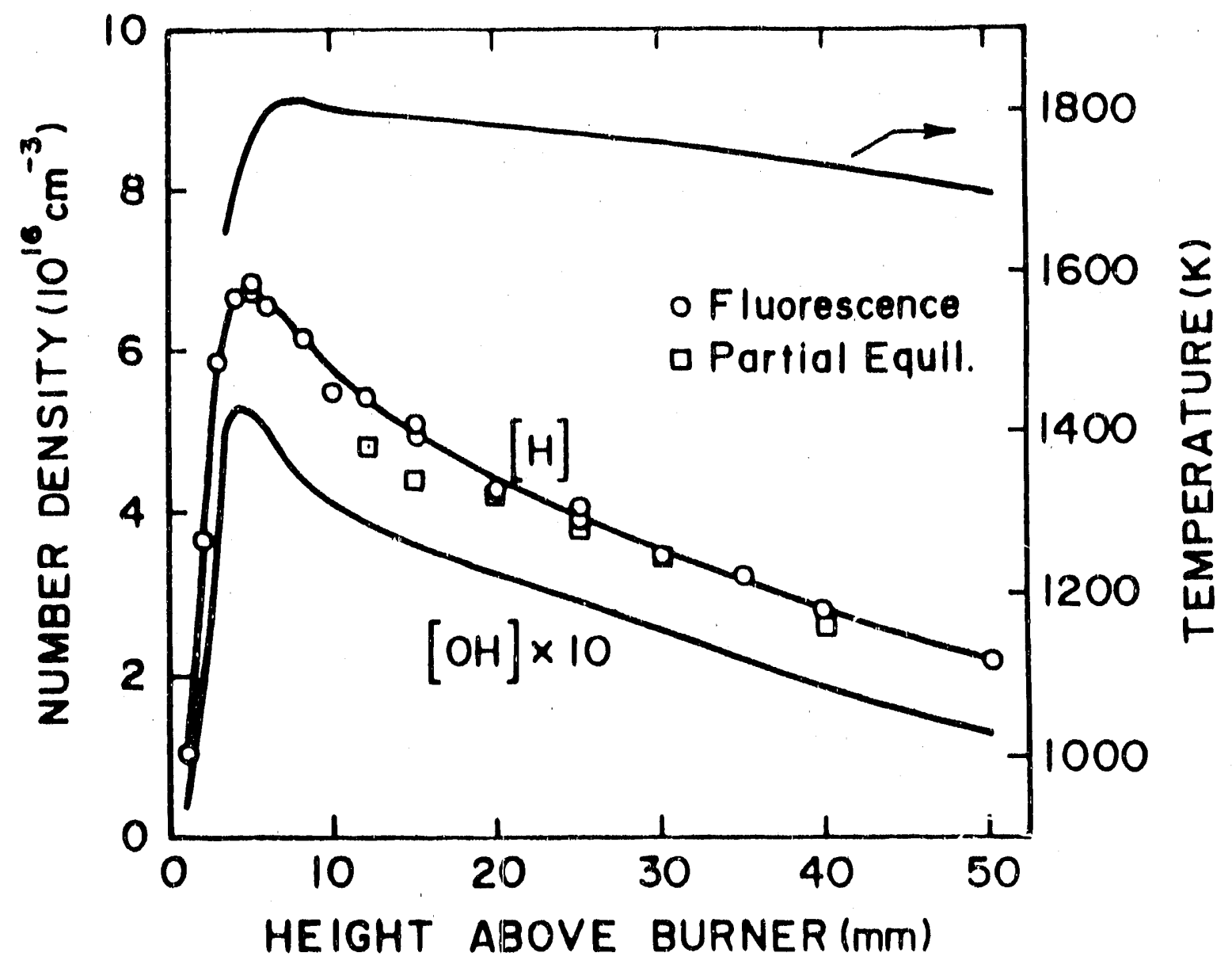

Fig. 2. Vertical number density profile of atomic hydrogen in the 72-Torr $\mathrm{C}_{2} \mathrm{H}_{4} / \mathrm{O}_{2} / \mathrm{Ar}$ fiame at $\Phi=1.7$. Also shown are the flame temperature and $\mathrm{OH}$ number density profiles. 


\section{Single-Laser Two-Step Detection of Atomic Hydrogen}

Two-step fluorescence schemes for detection of atomic hydrogen can offer more efficient excitation to upper electronic states and reduced photochemical disturbances $[15,16]$. The main disadvantage of such schemes is the need for two lasers to produce, for example, independently tunable 243-nm and 656-nm beams. In the course of performing our work on two-photon (205 $\mathrm{nm}$ ) excitation of atomic hydrogen, it occurred to us that an alternative two-step excitation scheme employing only a single laser should work for atomic hydrogen because of its unique energy-level structure. We refer to this single-laser, two-step scheme as SLATS.

The commercial availability of beta barium borate (BBO) crystals has made it practical to produce $243-\mathrm{nm}$ radiation by frequency-doubling a $486-\mathrm{nm}$ beam. Because of the nearly exact $1 / \mathrm{n}^{2}$ spacing of the atomic hydrogen energy levels, it is possible to employ the $243-\mathrm{nm}$ beam to excite the $1 \mathrm{~S}-2 \mathrm{~S}$ transition, and to use the residual $486-\mathrm{nm}$ beam to excite the $2 \mathrm{~S}-4 \mathrm{P}$ transition, followed by $486-\mathrm{nm}$ fluorescence detection from subsequent $4 \mathrm{P}-2 \mathrm{~S}$ radiative decay. Since we did not have a BBO crystal, we performed the ensuing experiments [17] in collaboration with J.E.M. Goldsmith at the Combustion Research Facility, Sandia National Laboratories, Livermore, California.

The experimental implementation is shown in Fig. 3. We used the 355-nm output from a Nd:YAG laser to pump a dye laser operated with Exciton LD489 dye. After frequency-doubling the dye-laser output with a BBO crystal, the 243-nm and 486-nm beams were separated by a Pellin-Broca prism, and focused into the flame chamber from opposite directions using $50-\mathrm{cm}$. 100-cm focal-length lenses. The low-pressure flames were stabilized on a 6 -cm-diameter, sintered stainless-steel water-cooled burner manufactured by McKenna Products. The 243-nm beam passed through a half-wave plate and a polarizer to control its intensity and to rotate its polarization to the vertical plane. The vertically polarized $486-\mathrm{nm}$ beam passed through a delay line (to match its path length to that of the $243-\mathrm{nm}$ beam); neutral density filters were employed 


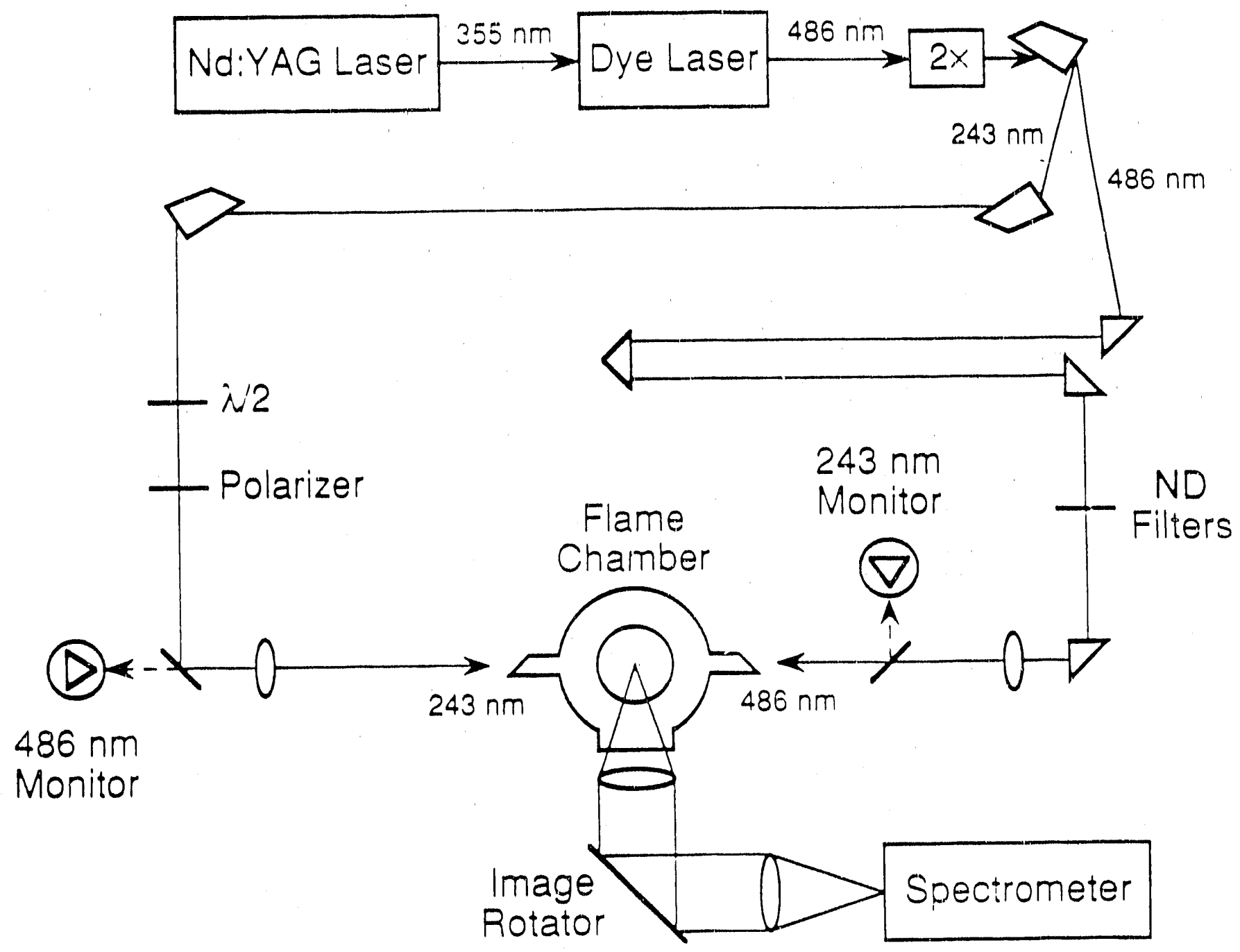

Fig. 3. Apparatus used for single-laser two-step Huorescence detection of atomic hydrogen in flames. 
to control its intensity. The fluorescence was collected at right angles to the laser beams, and either monitored by an interference filter-photomultiplier combination or by a $1 / 2$-meter spectrometer after image rotation by a pair of mirrors. Intensity dependences and flame profiles were recorded as 200-shot computer averages of the temporally integrated fluorescence signal measured using a boxcar averager.

The dependence of the SLATS signal on the pulse energies at $243 \mathrm{~nm}$ and at $486 \mathrm{~nm}$ was verified in a rich 20-Torr $\mathrm{H}_{2} / \mathrm{O}_{2} / \mathrm{Ar}$ Hame. For the former, the signal initially rises with an $\mathrm{I}^{2}$ dependence, but then increases less rapidly owing to rapid photoionization and partial saturation. For the latter, the fluorescence signal is linear with the 486-nm pulse energy for low energies, but then rapidly saturates.

To demonstrate the application of SLATS for flame studies [17], we measured relative atomic hydrogen fluorescence profiles in the same flames utilized in a previous comparative study of different $\mathrm{H}$-atom fluorescence techniques [16]. We outained excellent agreement with the previous two-laser, two-step (TLATS) profiles in all of the rich-to-lean $\mathrm{H}_{2} / \mathrm{O}_{2} / \mathrm{Ar}, \mathrm{H}_{2} / \mathrm{O}_{2} / \mathrm{N}_{2}$, $\mathrm{CH}_{4} / \mathrm{O}_{2}$ and $\mathrm{C}_{2} \mathrm{H}_{2} / \mathrm{O}_{2} / \mathrm{Ar}$ flames that had been studied previously. Figure 4 displays an example of this agreement, showing relative fluorescence profiles measured using both two-step methods in a lean $(\Phi=0.6), 72$-Torr $\mathrm{H}_{2} / \mathrm{O}_{2} / \mathrm{Ar}$ flame. The profiles are normalized at their peaks to the solid curve, which represents an absolute concentration profile calculated as described in Ref. 16. Because the quenching rate is essentially constant with position in the flame [11], we expect that the fluorescence profiles represent the actual relative $\mathrm{H}$-atom concentration profile.

In general, we find that the detection characteristics of TLATS and SLATS are very similar, primarily because both two-step techniques use $243-\mathrm{nm}$ radiation for the two-photon excitation step. Because both techniques also require detecting fluorescence at the same wavelength as one of the excitation beams, both can be affected by scattered laser radiation, especially in more hostile environments. Previous work [16] suggests that the greater reliability of relative flame 


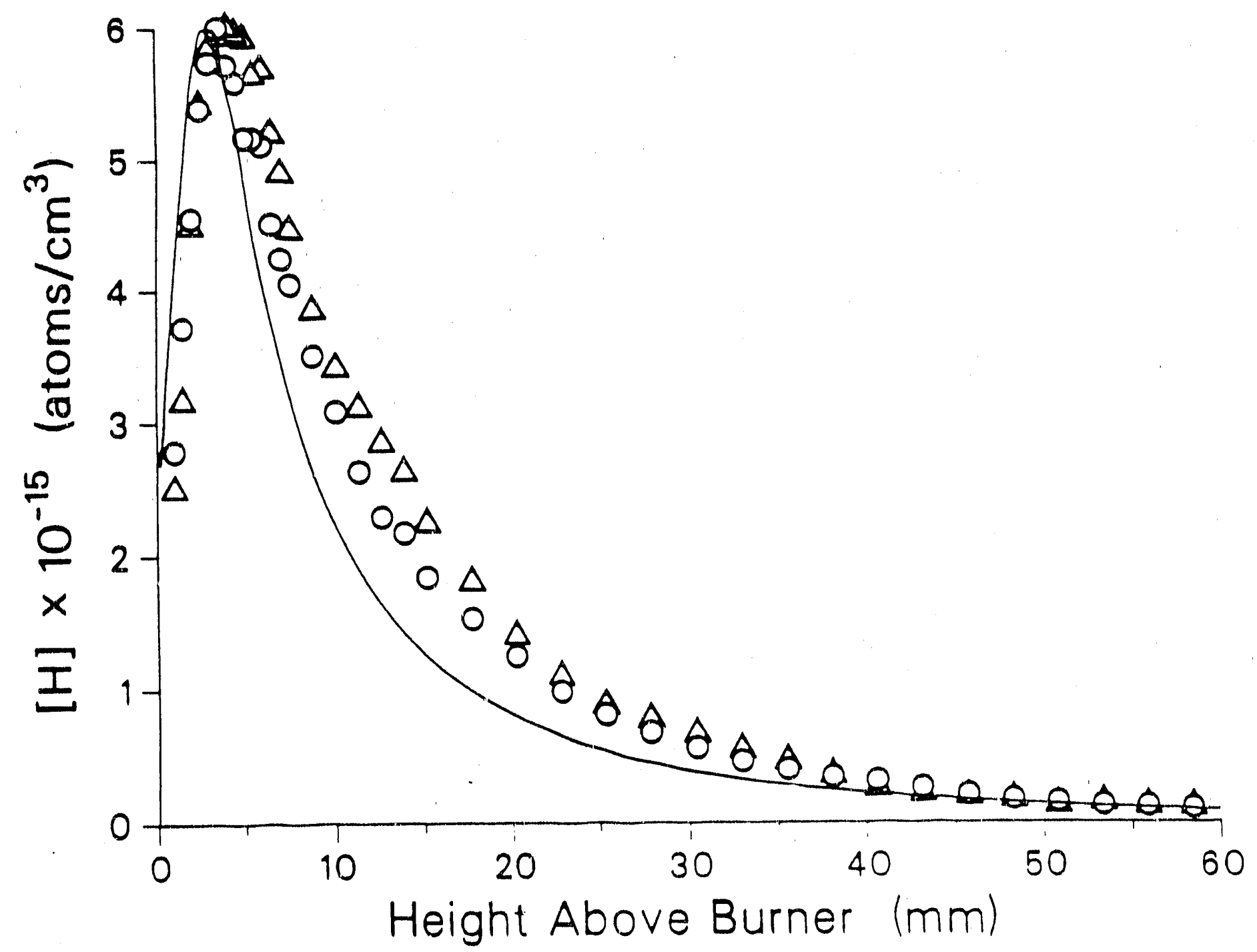

Fig. 4. Relative fuorescence profiles using two-laser (circles) and single-laser (triangles) twostep excitation in a lean $(\Phi=0.6), 72$ - Torr $\mathrm{H}_{2} / \mathrm{O}_{2} / \mathrm{Ar}$ flame, and absolute profile (solid curve) calculated using a flame model. 
profiles using TLATS compared to those measured using two-photon or three-photon excitation made the two-step technique the method of choice despite its additional experimental complexity. Fortunately, SLATS provides the reduced interferences and photochemical effects of TLATS without those additional complexities, and thus should prove useful for a wide range of flame studies.

\section{PICLS Study of Atomic-Hydrogen Quenching}

We have now completed work on the use of photoionization controlled-loss spectroscopy (PICLS) for the measureinent of the relative fluorescence transition probability $(A+Q)$ of atomic hydrogen in premixed flat $\mathrm{H}_{2} / \mathrm{O}_{2} / \mathrm{N}_{2}$ flames at 20 Torr [18]. For PICLS, a second beam is introduced that strongly photoionizes hydrogen atoms in the directly excited state via laserinduced absorption. This strong photoionization effectively eliminates the sensitivity of the fluorescence signal to quenching. Thus, the ratio of the fluorescence signal with PICLS to conventional fluorescence yields the ratio of the fluorescence transition probability to the rate coefficient for photoionization $[11,18]$. Normalized measurements of $A+Q$ can then be used to verify or establish limits with respect to the usual assumption that the rate coefficient for quenching is constant throughout the flame. This assumption can be addressed because at 20 Torr, the rate coefficient for quenching $(\mathrm{Q})$ is much greater than that for spontaneous emission (A).

In the PICLS experiments, a $205-\mathrm{nm}$ beam used for two-photon excitation to the $\mathrm{n}=3$ level of atomic hydrogen (see Fig. 1) is crossed by a second photoionizing beam (550 nm) whose intensity controls the photoionization rate. The $205-\mathrm{nm}$ beam is obtained from a dye laser pumped by a frequency-doubled Q-switched Nd:YAG laser. The frequency-doubled output from the dye laser at a wavelenght of $275 \mathrm{~nm}$ is split from the fundamental beam by a harmonic beam splitter and focused into a Raman cell. The output from the Raman cell is dirpersed by a Pellin-Broca prism, and the third anti-Stokes component $(205 \mathrm{~nm})$ is directed over the center of a 
flat-flame bumer. The fundamental (photoionizing) beam out the the dye laser $(550 \mathrm{~nm})$ is directed through a delay line and then also focused over the center of the flat-flame burner. Fluorescence from the directly excited state $(n=3)$ to the first excited state $(n=2)$ at $656 \mathrm{~nm}$ is isolated by a 3/4-m spectrometer. Conventional Huorescence measurements can be obtained by simply blocking the photoionizing beam.

The procedure for PICLS was substantiated by employing two tests. First, we measured the fluorescence voltage ratio at a constant pressure of 20 Torr for different values of the photoionizing beam power. Second, we held the power of the photionizing beam constant and measured the fluorescence voltage ratio at pressures ranging from 20 to 160 Torr. Both tests were conducted in the post-flame zone of a fuel-rich flame. All measurements were averaged over 600 laser shots. The first test showed that PICLS correctly predicts the change in the fluorescence signal as a function of the rate coefficient for photoionization. The second test confirmed that (1) quenching can be modeled with an average cross-section that is independent of pressure and (2) PICLS is useful in measuring the influence of quenching on the fluorescence signal. The major conclusion is that the rate coefficient for quenching is directly proportional to pressure and inversely proportional to the square-root of the temperature, as predicted by kinetic theory.

Figure 5 shows vertical profiles of the fluorescence transition probability for atomic hydrogen in fuel-rich and stoichiometric flames at 20 Torr. Also shown are vertical profiles of the absolute number density of atomic hydrogen measured with PICLS, along with vertical profiles of other major species obtained from partial equilibrium calculations and atom balances in the post-flame zone $[11,14]$. The transition probabilities were obtained by determining the fluorescence voltage ratio from two sets of vertical fluorescence profiles, one conventional and the other with PICLS; the resulting transition probabilities were then normalized in the postflame zone. The two solid curves through the data are the predicted trends in the transition probabilities from kinetic theory. The assumption of a constant average cross-section clearly 


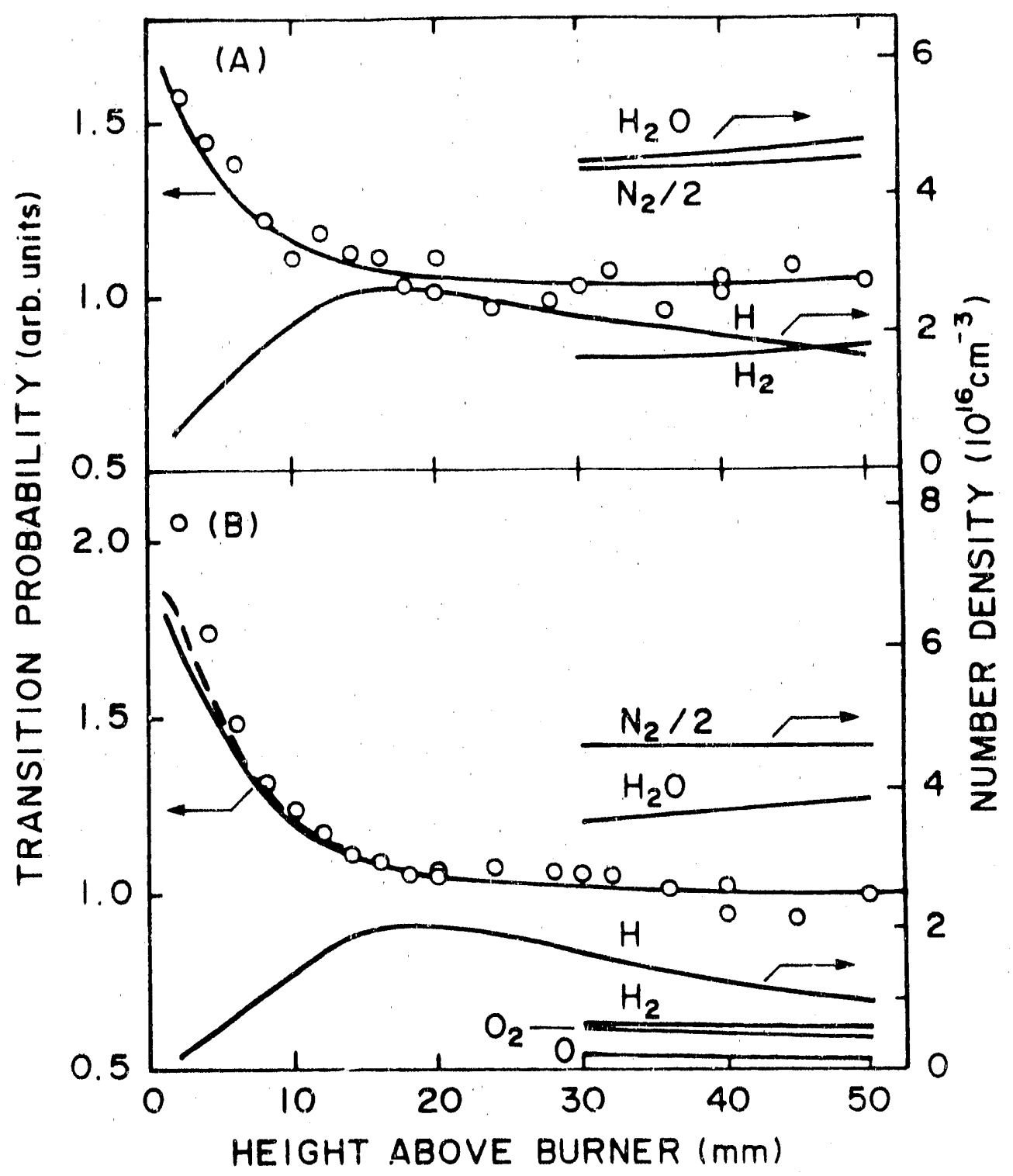

Fig. 5. Vertical profiles of the fluorescence transition probability for atomic hydrogen in (A) fuel-rich and (B) stoichiometric $\mathrm{H}_{2} / \mathrm{O}_{2} / \mathrm{N}_{2}$ flames at 20 Torr. The quenching rate coefficient for the calculated transition probability (solid curve) is obtained from kinetic theory assuming a constant average cross-section. The dashed line in (B) is the limiting case of no contribuiton by spontaneous emission to the transition probability. The curves from 30-50 mm are determined from partial-equilibrium calculations. 
predicts the correct trend for the fluorescence transition probability in both flames. Although the magnitude of the growth in the transition probability when approaching the burner is underpredicted in the stoichiometric flame, the prediction matches the data in the preheat zone of the fuel-rich flame. The underprediction is probably related to the decreasing number density of the dominant quencher $\left(\mathrm{H}_{2} \mathrm{O}\right)$ in the preheat zone [18]. In general, the results demonstrate the utility of PICLS for measuring relative changes in the fluorescence transition probability at flame conditions.

\section{Review of Light-Scattering Methods for Thermometry}

The previous DOE-supported work on temperature measurements by anomalous $[12,13]$ and laser-saturated [i?] fluorescence has led to publication of a major review paper on thermometric light-scattering methods [20]. This paper will also be reproduced in a forthcoming book entitled Combustion Measurements, which will by edited by N. Chigier and published by Hemisphere. This book will review the state-of-the-art with respect to instruments and measurements in combustion systems.

The paper reviews thermometric methods based on spontaneous Raman scattering, Rayleigh scattering and laser-induced fluorescence [18]. The typical petformance of these light-scattering methods at flame temperatures based on experiments to date in steady laminar flows shows an accuracy/precision of $2 \%$ for vibrational Raman, $0.3 \%$ for rotational Raman, and $1 \%$ for both Rayleigh scattering and fluorescence. The differential cross-sections for both vibrational and rotational Raman scattering are too low for useful applications to planar thermometry. Even for local measurerrents, care must be exercised to avoid laser-induced luminosity and scattered light. Similar problems can arise when employing Rayleigh scattering, although in this case a larger wross-section can support the extension to planar thermometry under "particle-free" conditions. 
Temporally-resolved planar thermometry favors the fluorescence methods because of their intrinsically high $\mathrm{S} / \mathrm{N}$ ratio. Such methods are often required in turbulent flows because of the need for nonintrusive measurements with high spatial and temporal resolution. Unfortunately, the normal two-line excitation schemes are plagued by experimental complications accompanying utilization of two laser beams. Monochromatic methods, such as the thermallyassisted or absolute fluorescence techniques, show great potential in this regard, but further development is necessary. Local, thermally-assisted thermometry, utilizing stable molecular species should be pursued to assess the extent to which the accuracy and precision of the atomic case carries over to the molecular case.

Measurements at lower temperatures $(T<500 \mathrm{~K})$ are not feasible using atomic seeds because of their low vapor pressure. Precision and accuracy to $\pm 1 \mathrm{~K}$ is possible near room temperature and to $\pm 5 \mathrm{~K}$ at temperatures to $1000 \mathrm{~K}$ using rotational Raman scattering. Similar results appear possible for fluorescence thermometry by using stable molecular species such as NO or $I_{2}$. Thus far, low-temperature fluorescence thermometry has only been attempted with the two-line excitation approach. Low-temperature planar thermometry may be possible using thermallyassisted fluorescence of $\mathrm{NO}$ or $\mathrm{I}_{2}$ or perhaps anomalous fluorescence from pyrene. Accuracy and precision to at least $\pm 1 \%$ appear feasible for steady laminar flows.

\section{LSF Measurements of Nitric Oxide}

Previously, we have made LSF measurements of $\mathrm{OH}$ and $\mathrm{NH}$ [1-7]. However, LSF measurements of NO are considered problematic because of its smaller rotational constant, which tends to increase the rotational relaxation rate and thus reduces the efficacy of the balanced cross-rate model. To as: ess the feasibility of LSF measurements for NO, we have determined its broadband fluorescence signal as a function of laser power under flame conditions. The resulting saturation curve is similar to that for $\mathrm{OH}$, thus suggesting that LSF may be useful for concentration measurements of nonhydrogenic diatomics such as NO. 
Relative NO fuorescence profiles in 'ean and rich flames confirm this suggestion.

The NO fluorescence data were obtained at atmospheric pressure using the optical configuration shown in Fig 6. For excitation of NO transitions in the $A^{2} \Sigma^{+}-X^{2} \Pi(0,0)$ band, we require laser radiation at $-226 \mathrm{~nm}[21-24]$. Suitable narrowbanc radiation can be obtained by employing the second harmonic $(\lambda=532 \mathrm{~nm})$ of a Quanta-Ray DCR-3G Nd:YAG laser, narrowing the linewidth with an intracavity etalon, and pumping a PDL-2 dye laser. The dye laser uses a mixture of Exciton Rhodamine 590 and 610 dyes to achieve high conversion efficiency of the $532-\mathrm{nm}$ radiation. We have obtained laser energies of $-100 \mathrm{~m} / \mathrm{pulse}$ at 572 $\mathrm{nm}$, with an input energy of $-370 \mathrm{~mJ} / \mathrm{pulse}$ at $53^{\circ} \mathrm{nm}$. The output of the dye laser is frequency doubled and the doubled-dye beam is mixed with the first harmonic of the Nd:YAG laser $(\lambda=$ $1064 \mathrm{~nm}$ ) in a Quanta-Ray Wavelength Extender (WEX-1). The colinear beams (1064, 572, 286 , and $226 \mathrm{~nm}$ ) are then dispersed with a Pellin-Broca puism, and the desired 226-nm beam is raised to the appropriate height with a prism assembly within the WEX. Because of the large pulse energy from the dye laser, we have obtained as much as $-6 \mathrm{~mJ} / \mathrm{pulse}$ at $226 \mathrm{~nm}$.

To attenuate the beam, which is necessary to determine the level of saturation, we rely on quartz plates as well as neutral density filters. For increased attenuation, we replace the turning mirror (see Fig. 6) with an ordinary optical-glass flat; the beam attenuation is then determined by the reflectivity of the material. The transmission of the various attenuators was measured using Rayleigh scattering in room-temperature air. An aperture placed before the focussing lens is used to block scattered radiation. To minimize reflections from the vessel entrance and exit ports, we use windows placed at Brewster's angle. Finally, a portion of the beam is directed to two silicon UV-sensitive PIN photodiodes (Hamamatsu S17722-02), which are used to monitor the shot-to-shot fluctuations of the UV beam energy and to trigger the detection electronics.

For fluorescence detection, we use the two ports adjacent to the laser entrance and exit ports (Fig. 6). Fluorescence from one port is focused on the vertical entrance slit of a $1 / 4-\mathrm{m}$ 


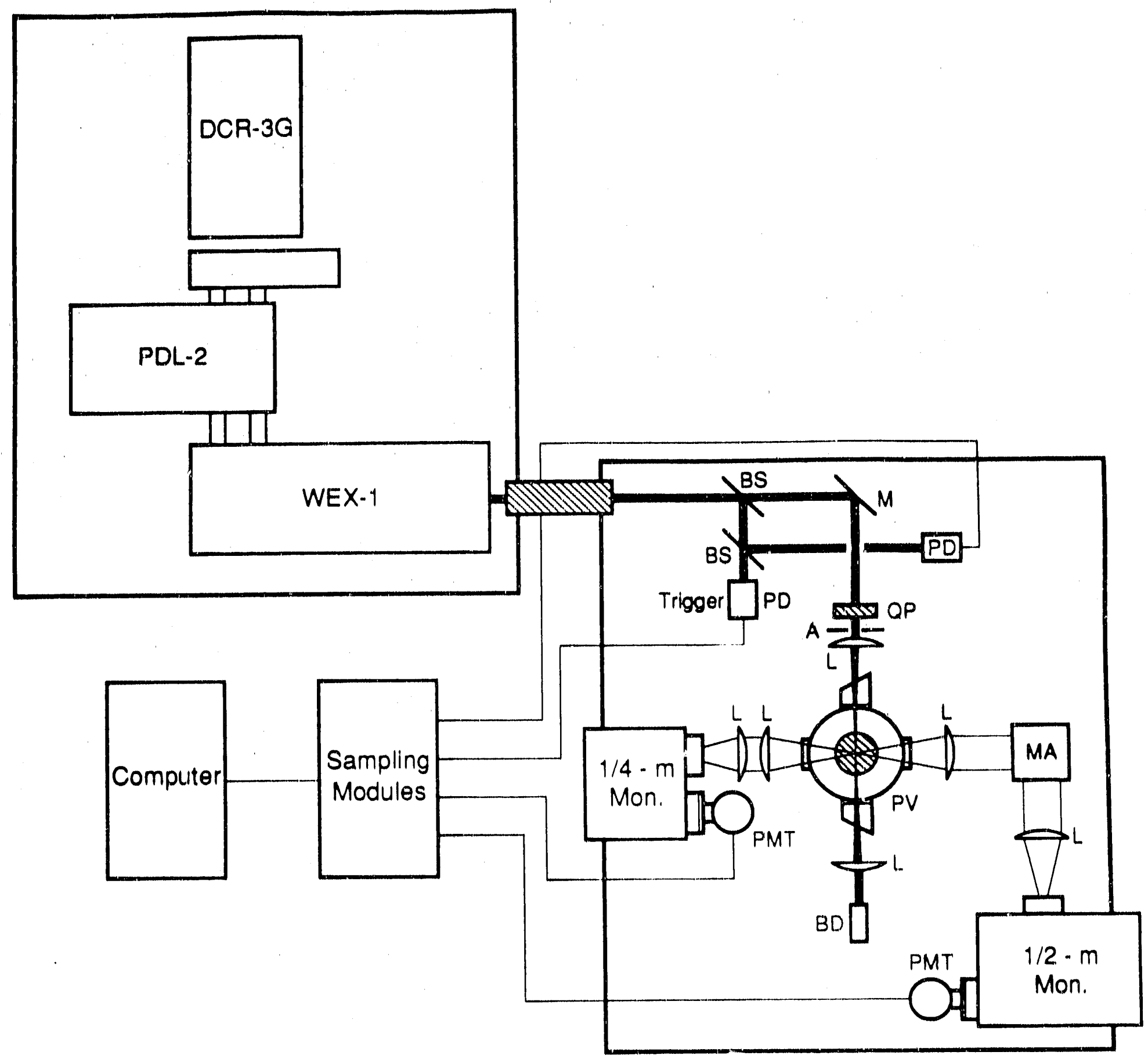

Fig. 6. Schematic for LIF experiments. Components: A-aperture; BD-beam dump; BS-beam splitter; L-lens; M-turning mirror, MA-image rotating mirror assembly; ND-neutral density filter(s); PD-photodiode; PMT-photomultiplier tube; QP-quartz plate(s); PVpressure vessel. 
monochromator, employing an RCA 1P28 photomultiplier tube. Through the opposite port, fluorescence is rotated by $90^{\circ}$ with a mirror assembly (using mirrors with a magnesium fluoride overcoat) and then focused on the entrance slit of a $1 / 2-\mathrm{m}$ monochromator. This monochromator employs a specially-wired RCA 1P28B photomultiplier tube for detection of the spectrally resolved fluorescence signals. Whereas the primary use of the $1 / 2-\mathrm{m}$ monochromator is for saturated fluorescence experiments, where spectral and temporal resolution is important, the 1/4-m monochromator is less sensitive to beam steering and thus more appropriate for generating excitation spectra.

The PMT and photodiode signals are recorded with Stanford Research Systems equipment; for the saturated fluorescence experiments (with the 1/2-m monochromator), the PMT signals are resolved with the 500-ps sampling gate of the SR255 fast sampler, which is centered temporally at the peak of the fluorescence pulse using an SR200 gate scanner. We also use two SR250 gated integrators to capture signals from the second PMT (attached to the 1/4-m monochromator) and the PIN photodiode monitoring the UV beam energy. The output voltages from the fast sampler and the two gated integrators are then digitized and stored with the SR 245 computer interface module and the SR265 software package, which also allows programmed movement of laboratory stepper motors.

The saturation curves shown in Fig. 7 were obtained at atmospheric pressure. For this experiment, we used a lean $(\Phi=0.77)$ premixed laminar $\mathrm{C}_{2} \mathrm{H}_{6} / \mathrm{O}_{2} / \mathrm{N}_{2}$ flame stabilized on a sintered bronze, flat flame McKenna burner. Because of the small NO concentration in these flames [25], we added -40 ppm of NO to the reactants. The NO was excited using the $R_{1}(16.5)$ line of the $(0,0)$ band $(\lambda=225.61 \mathrm{~nm})$. The fluorescence signal was then monitored using the $1 / 2-\mathrm{m}$ monochromator. Rather than trying to isolate a single line in detection, we positioned the monochromator at $-236.5 \mathrm{~nm}$ and collected fluorescence from the $(0,1)$ band within the $-1-\mathrm{nm}$ bandwidth of the monochromator. For the measurements shown in Fig. 7, we used three entrance slit widths $(60 \mu \mathrm{m}, 100 \mu \mathrm{m}$, and $130 \mu \mathrm{m})$ and a constant slit height of $10 \mathrm{~mm}$. Furthermore, 


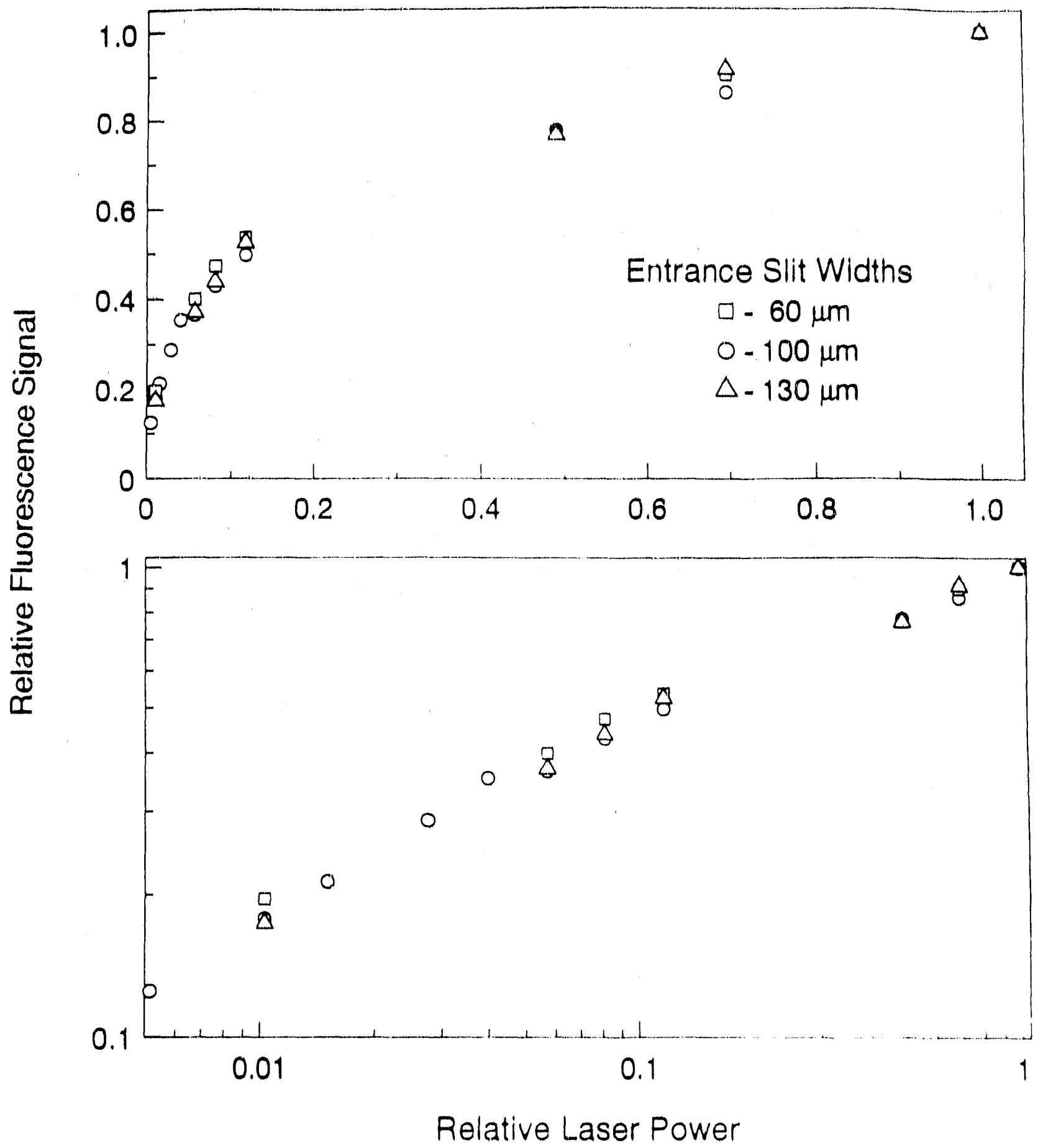

Fig. 7. Saturation curves of NO in the postflame region of a lean $(\Phi=0.77)$ atmospheric premixed laminar $\mathrm{C}_{2} \mathrm{H}_{6} / \mathrm{O}_{2} / \mathrm{N}_{2}$ flame. 
each data point is the average fluorescence signal from 900 laser shots. Frr 1 Fig. 7, we observed that partial saturation is achieved over a large range of laser power; this is especially evident on the $\log -\log$ plot. In addition, from the saturation curves, we see that the entrance slit width does not affect significantly the degree of saturation (i.e., the sensitivity of the fluorescence signal to laser power) for the range of slit widths and laser powers examined.

In Fig, 8, we show the relative NO concentration profiles for two atmospheric premixed laminar $\mathrm{C}_{2} \mathrm{H}_{6} / \mathrm{O}_{2} / \mathrm{N}_{2}$ flames. The lean flame had $\Phi=0.77$ (with a dilution ratio of 3.0 and a cold-gas flow rate of $17.6 \mathrm{slm}$ ) while the rich flarme had $\Phi=1.2$ (with a dilution ratio of 3.0 and a cold gas flow rate of $18.1 \mathrm{~s} / \mathrm{m})$. As with the saturation measurements, the fluorescence was collected with the $1 / 2-m$ monochromator, with the signal averaged over 900 laser shots. Due to the partial saturation of the NO, the fluorescence signal is rather insensitive to changes in the quenching environment; thus, the ratio of the fluorescence signals for the two flames should give approximately the ratio of NO concentrations (since we expect that the temperatures for the two flames do not differ significantly). In both flames, the NO production occurs primarily in the flame front, where the flame radicals exist in superequilibrium concentrations [25].

\section{EFFORT OF RESEARCH PERSONNEL}

Professor Laurendeau devoted approximately $5 \%$ of his time to the project during the academic year and $10 \%$ during the summer. J. Thaddeus Salmon worked half-time as a Ph.D. candidate until he left in August, 1986. During this time, he was primarily responsible for the work on atomic hydrogen and PICLS. Paul A. Nagy was responsible for the initial work on laser-saturated fluorescence measurements of NO. Campbell D. Carter completed the NO work during the initial portions of a post-doctoral appointment. 


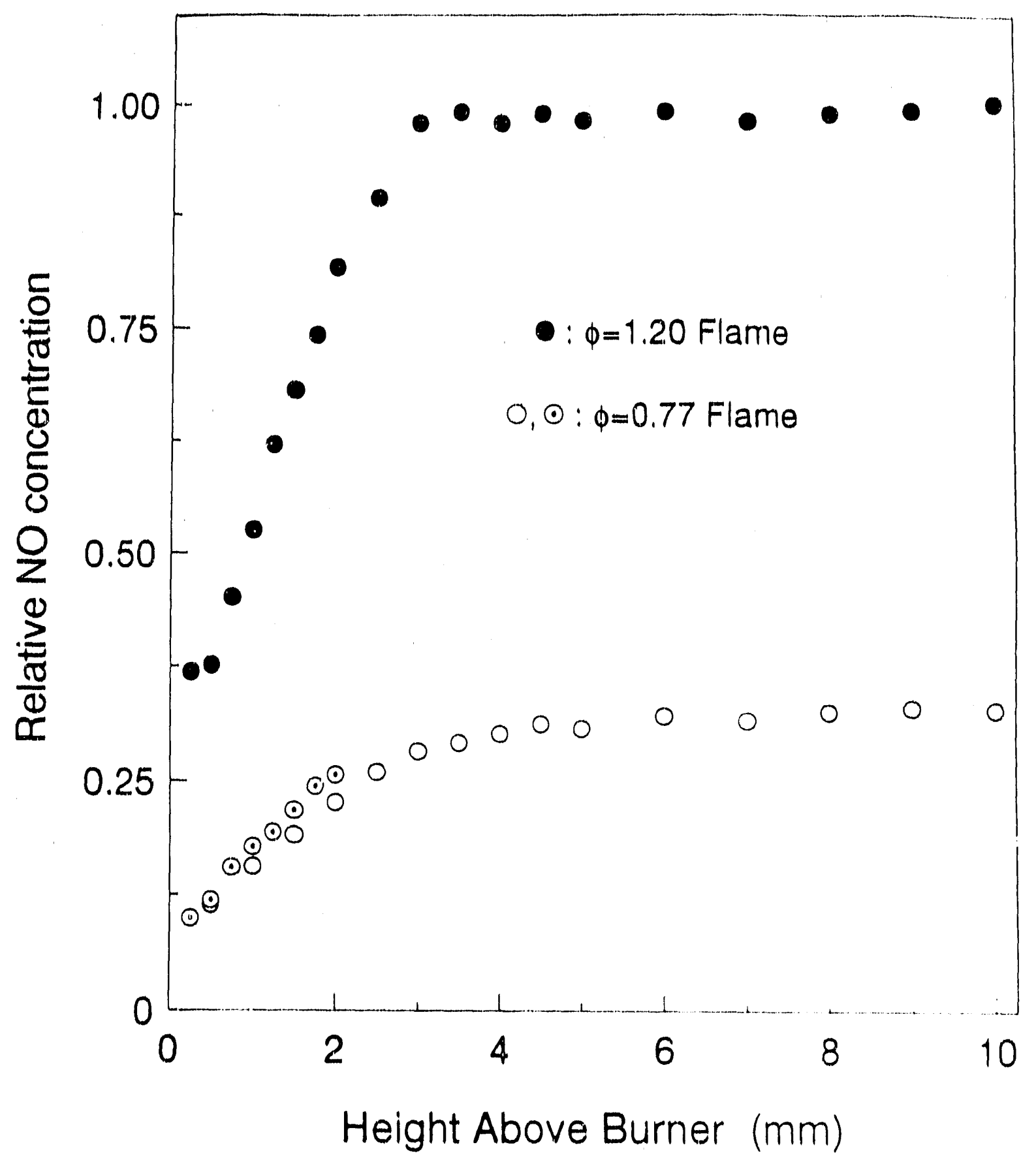

Fig. 8. Relative concentrations of $\mathrm{NO}$ in two atmospheric premixed laminar $\mathrm{C}_{2} \mathrm{H}_{6} / \mathrm{O}_{2} / \mathrm{N}_{2}$ flarnes as a function of height above the burner. The lean flame had $\Phi=0.77$, a dilution ratio of 3.0, and a cold-gas flow rate of $17.6 \mathrm{~s} / \mathrm{m}$, while this rich flame had $\Phi=1.2$, a dilution ratio of 3.0, and a cold gas flow rate of $18.1 \mathrm{~s} / \mathrm{m}$. 


\section{PUBLICATION AND PRESENTATION OF WORK}

\section{Refereed Articles}

[1] R.P. Lucht and N.M. Laurendeau, "Comment on 'Laser-Induced Fluorescence Measurement of Sodium in Flames," Combustion and Flame 34, 215 (1979).

[2] R.P. Lucht and N.M. Laurendeau, "Two Level Model for Near Saturated Fluorescence in Diatomic Molecules," Applied Optics 18.856 (1979).

[3] R.F. Lucht, D.W. Sweeney and N.M. Laurendeau, "Saturated Fluorescence Measurements of the Hydroxyl Radical," in Laser Probes for Combustion Chemistry, D.R. Crosley, Ed., American Chemical Society, Washington, D.C., 145 (1980).

[4] R.P. Lucht, D.W. Sweeney and N.M. Laurendeau, "Balanced Cross-Rate Model for Saturated Molecular Fluorescence in Flames," Applied Optics 19, 3295 (1980).

[5] R.P. Lucht, D.W. Sweeney and N.M. Laurendeau, "Temperature Measurement by Two. Line Laser-Saturated OH Fluorescence in Flames," Applied Optics 21, 3729 (1982).

[6] R.P. Lucht, D.W. Sweeney and N.M. Laurendeau, "Laser-Saturated Fluorescence Measurements of $\mathrm{OH}$ Concentration in Flames," Combustion and Flame 50, 189 (1983).

[7] R.P. Lucht, J.T. Salmon, G.B. King, D.W. Sweeney and N.M. Laurendeau, "Two-PhotonExcited Fluorescence Measurement of Hydrogen Atoms in Flames," Optics Letters 8, 365 (1983).

[8] J.T. Salmon, R.P. Lucht, D.W. Sweeney and N.M. Laurendeau, "Laser-Saturated Fluorescence measurements of $\mathrm{NH}$ in a Premixed Subatmospheric $\mathrm{CH}_{4} / \mathrm{N}_{2} \mathrm{O} / \mathrm{Ar}$ Flame," Twentieth (International) Symposium on Combustion. The Combustion Institute, Pittsburgh, Pa, 1187 (1984).

[9] R.P. Lucht, D.W. Sweeney, N.M. Laurendeau, "Laser-Saturated Fluorescence Measurements of $\mathrm{OH}$ in Atmospheric Pressure $\mathrm{CH}_{4} / \mathrm{O}_{2} / \mathrm{N}_{2}$ Flames under Sooting and Non-Sooting Conditions," Combustion Science and Technology 42, 259 (1985).

[10] J.T. Salmon and N.M. Laurendeau, "Calibration of Laser-Saturated Fluorescence Measurements using Rayleigh Scattering," Applied Optic's 24, 65 (1985).

[11] J.T. Salmon and N.M. Laurendeau, "Analysis of Probe Volume Effects Associated with Laser-Saturated Fluorescence Measurements," Applied Optic's 27, 1313 (1985).

[12] D.L. Peterson, F.E. Lytle, and N.M. Laurendeau, "Determination of Mixed Polynuclear Aromatic Hydrocarbons in the Vapor Phase by Laser-Induced Fluorescence Spectrometry," Analytica Chimica Acta 174, 133 (1985).

[13] D.L. Peterson, F.E. Lytle and N.M. Laurendeau, "Determination of Flame Temperature Using the Anomalous Fluorescence of Pyrene," Optics Letters 11, 34 9 (1986).

[14] J.T. Salmon and N.M. Laurendeau, "Quenching-Independent Fluorescence Measurements of Atomic Hydrogen with Photoionization Controlled-Loss Spectroscopy," Optics Letters II, 419 (1986). 
[15] R.P. Lucht, D.W. Sweeney and N.M. Laurendeau, "Time-Resolved Fluorescence Investigation of Rotational Transfer in $\mathrm{A}^{2} \Sigma^{+}(v=0) \mathrm{OH}, "$ Applied Optics 25, 4086 (1986).

[16] J.T. Salmon and N.M. Laurendeau, "Absolute Concentration Measurements of Atomic Hydrogen in Subatmospheric Premixed $\mathrm{H}_{2} / \mathrm{O}_{2} / \mathrm{N}_{2}$ Flat Flames with Photolonization Controlled-Loss Spectroscopy," Applied Optics 26, 2881 (1987).

[17] D.L. Peterson, F.E. Lytle and N.M. Laurendeau, "Flame Temperature Measurements Using the Anomalous Fluorescence of Pyrene," Applied Optics 27, 2768 (1988).

[18] J.T. Salmon and N.M. Laurendeau, "Concentration Measurements of Atomic Hydrogen in Subatmospheric Premixed $\mathrm{C}_{2} \mathrm{H}_{4} / \mathrm{O}_{2} / \mathrm{Ar}$ Flat Flames," Combustion and Flame 74, 221 (1988).

[19] N.M. Laurendeau, "Temperature Measurements by Light-Scattering Methods," Progress in Energy and Combustion Science 14, 147 (1988).

[20] J.T. Salmon and N.M. Laurendeau, "Relative Fluorescence-Quenching Measurements of Atomic Hydrogen in Subatmospheric $\mathrm{H}_{2} / \mathrm{O}_{2} / \mathrm{N}_{2}$ Flames with Photoionizatior ControlledLoss Spectroscopy," Journal of Quantitative Spectroscopy and Radiative Transfer 43, 155 (1990).

[21] J.E.M. Goldsmith and N.M. Laurendeau, "Single-Laser Two-Step Fluorescence Detection of Atomic. Hydrogen in Flames," Optics Letters 15, 576 (1990).

2. Theses

[1] R.P. Lucht, "Measurement of Diatomic Flame Radicals via Absorption and Saturated Fluorescence Spectroscopy: Theoretical Calculations and Preliminary Experimental Results," M.S. Thesis, School of Mechanical Engineering, Purdue University, West Lafayette, Indiana, August, 1979.

[2] R.P. Lucht, "Experimental and Theoretical Investigation of Laser Saturated $\mathrm{OH}$ Fluorescence in Flames," Ph.D. Thesis, School of Mechanical Engineering, Purdue University, West Lafayette, Indiana, December, 1981.

[3] P.D. Ludington, "Laser-Induced Fluorescence Measurements of Polycyclic Aromatic Hydrocarbons in a Vapor Cell at 297-383 K," M.S. Thesis, School of Mechanical Engineering, Purdue University, West Lafayette, Indiana, December, 1982.

[4] J. T. Salmon, Jr., "Quantitative Fluorescence Measurements of Atomic Hydrogen in Flames via Two-Photon Absorption," Ph.D. Thesis, School of Mechanical Engineering, Purdue University, West Lafayette, Indiana, August, 1986.

[5] D.L. Peterson, "Laser-Induced Fluorescence Measurements of Vapor-Phase Polycyclic Aromatic Hydrocarbons," Ph.D. Thesis, Department of Chemistry, Purdue University, West Lafayette, Indiana, August, 1987. 


\section{Meeting Presentations}

[1] R.P. Lucht, D.W. Sweeney and N.M. Laurendeau, "Saturated Fluorescence Measurements of the Hydroxyl Radical," 178th Meeting of the American Chemical Society, Washington, D.C., September, 1979.

[2] R.P. Lucht, D.W. Sweeney and N.M. Laurendeau, "Saturated Fluorescence Measurement of OH in Subatmospheric Flat Flames," 35th Symposium on Molecular Spectroscopy, Ohio State University, Columbus, Ohio, June, 1980.

[3] R.P. Lucht, D.W. Sweeney and N.M. Laurendeau, "Time-Resolved Study of OH Saturated Fluorescence," Gordon Conference on the Chemistry and Physics of Laser Diagnostics in Combustion, Plymouth, New Hampshire, June, 1981.

[4] R.P. Lucht, N.M. Laurendeau and D.W. Sweeney, "Saturated Fluorescence Measurements of $\mathrm{OH}$ in $\mathrm{H}_{2} / \mathrm{O}_{2} / \mathrm{N}_{2}$ Flat Flames," Eastern States Section Meeting, The Combustion Institute, Carnegie-Mellon University, Pittsburgh, Pennsylvania, October, 1981.

[5] R.P. Lucht, D.W. Sweeney and N.M. Laurendeau, "Laser Saturated Fluorescence Measurements of OH Concentration in Flames," Spring Meeting, Western States Section, The Combustion Institute, University of Utah, Jalt Lake City, Utah, April, 1982.

[6] R.P. Lucht, D.W. Sweeney and N.M. Laurendeau, "Laser Saturated Fluorescence Measurements of $\mathrm{OH}$ Concentration and Rotational Temperature in Flames," Conference on Lasers and Electro-Optics (CLEO '82), Phoenix, Arizona, April, 1982.

[7] R.P. Lucht, D.W. Sweeney, N.M. Laurendeau, "Laser-Saturated Fluorescence Measurements of $\mathrm{OH}$ in Sooting, Atmospheric Pressure $\mathrm{CH}_{4} / \mathrm{O}_{2} / \mathrm{N}_{2}$ Flames," Fall Meeting, Western States Section, The Combustion Institute, Sandia National Laboratory, Livermore, California, October, 1982.

[8] J.T. Salmon, R.P. Lucht, D.W. Sweeney, N.M. Laurendeau, "Laser-Saturated Fluorescence Measurements of $\mathrm{NH}$ in a Premixed Subatmospheric $\mathrm{CH}_{4} / \mathrm{N}_{2} \mathrm{O} / \mathrm{Ar}$ Flame," Fall Meeting, Western States Section, The Combustion Institute, Sandia National Laboratory, Livermore, California, October, 1982.

[9] R.P. Lucht, J.T. Salmon, D.W. Sweeney, and N.M. Laurendeau, "Rotational Relaxation Cross-Sections for $\mathrm{OH}$ in Flames," Gordon Conference on the Chemistry and Physics of Laser Diagnostics in Combustion, Plymouth, New Hampshire, July, 1983.

[10] J.T. Salmon and N.M. Laurendeau, "Analysis of Probe Volume Effects Associated with Laser-Saturated Fluorescence Measurements," Spring Meeting, Western States Section, The Combustion Institute, Boulder, Colorado, April, 1984.

[11] R.P. Lucht, D.W. Sweeney and N.M. Laurendeau, "Time-Resolved Fluorescence Investigation of Rotational Transfer in $\mathrm{A}^{2} \Sigma^{+}(\mathrm{v}=0) \mathrm{OH}, "$ Fall Meeting, Western States Section, The Combustion Institute, Stanford, California, October, 1984.

[12] N.M. Laurendeau, J.T. Salmon, G.B. King and C.D. Carter, "Measurement of Species Concentration in High-Pressure Flames by Laser-Saturated Fluorescence," Gordon Conference on the Chemistry and Physics of Laser Diagnostics in Combustion," New London, New Hampshire, July, 1985. 
[13] N.M. Laurendeau, "Concentration Measurements in Practical Flames by Laser-Saturated Fluorescence," Fall Meeting, Eastem States Section, The Combustion Institute, Philadelphia, Pennsylvania, November, 1985.

[14] D.L. Peterson, F.E. Lytle and N.M. Laurendeau, "Flame Temperature Measurements Using Pyrene Fluorescence," Pittsburgh Conference on Analytical Chemistry, Atlantic City, New Jersey, March, 1986.

[15] J.T. Salmon and N.M. Laurendeau, "Quenching-Independent Fluorescence Measurements of Atomic Hydrogen with Photoionization Controlled-Loss Spectroscopy," Spring Meeting, Central States Section, The Combusticn Institute, Cleveland, Ohio, May, 1986.

[16] N.M. Laurendeau, "Temperature Measurements by Light-Scattering Methods," Symposium on Developments in Experimental Techniques in Heat Transfer and Combustion, Twenty-Fuurth National Heat Transfer Conference, Pittsburgh, Pennsyivania, August, 1987.

[17] D.L. Peterson, F.E. Lytle and N.M. Laurendeau, "Flame Temperature Measurements Using the Anomalous Fluorescence of Pyrene," Fall Meeting, Eastern States Section, The Combustion Institute, Gaithersburg, Maryland, November, 1987.

[18] N.M. Laurendeau, "Temperature Measurements by Light-Scattering Methods," Spring Meeting, Central States Section/The Combustion Institute, Indianapolis, Indiana, May, 1988. 


\section{REFERENCES}

[1] R.P. Lucht, D.W. Sweeney and N.M Laurendeau, "Laser-Saturated Fluorescence Measurements of $\mathrm{OH}$ Concentration in Flames," Combustion and Flame 50, 189 (1983).

[2] R.P. Lucht, D.W. Sweeney, N.M. Laurendeau, "Laser-Saturated Fluorescence Measurements of $\mathrm{OH}$ in Atmospheric Pressure $\mathrm{CH}_{4} / \mathrm{O}_{2} / \mathrm{N}_{2}$ Flames under Sooting and Non-Sooting Conditions," Combustion Science and Technology 50, 259 (1985).

[3] J.T. Salmon and N.M. Laurendeau, "Calibration of Laser-Saturated Fluorescence Measurements using Rayleigh Scattering," Applied Optics 24, 65 (1985).

[4] J.T. Salmon and N.M. Laurendeau, "Analysis of Probe Volume Effects Associated with Laser-Saturated Fluorescence Measurements," Applied Optics 24, 1313 (1985).

[5] R.P. Lucht, D.W. Sweeney, N.M. Laurendeau, M.C. Drake, M. Lapp, and R.W. Pitz, "Single Pulse Laser-Saturated Fluorescence Measurements of $\mathrm{OH}$ in Turbulent Nonpremixed Flames," Optics Letters 9, 90 (1984).

[6] M.C. Drake, R.W. Pitz, M. Lapp, C.P. Fenimore, R.P. Lucht, D.W. Sweeney, and N.M. Laurendeau, "Measurement of Superequilibrium Hydroxyl Concentrations in Turbulent Nonpremixed Flames using Saturated Fluorescence," Twentieth Symposium (International) on Combustion, The Combustion Institute, Pittsburgh, Pennsylvania, 327 (1984).

[7] J.T. Salmon, R.P. Lucht, D.W. Sweeney, N.M. Laurendeau, "Laser-Saturated Fluorescence Measurements of $\mathrm{NH}$ in a Premixed Subatmospheric $\mathrm{CH}_{4} / \mathrm{N}_{2} \mathrm{O} / \mathrm{Ar}$ Flame," Twentieth Symposium (International) on Combus:ion. The Combustion Institute, Pittsburgh, Pennsylvania, 1187 (1984).

[8] R.P. Lucht, J.T. Salmon, G.B. King, D.W. Sweeney and N.M. Laurendeau, "Two-PhotonExcited Fluorescence Measurement of Hydrogen Atoms in Flames," Optics Letters 8, 365 (1983).

[9] D.L. Peterson, F.E. Lytle and N.M. Laurendeau, "Determination of Mixed Polynuclear Aromatic Hydrocarbons in the Vapor Phase by Laser-Induced Fluorescence Spectrometry," Analytica Chimica Acta 174, 133 (1985).

[10] J.T. Salmon and N.M. Laurendeau, "Quenching-Independent Fluorescence Measurements of Atomic Hydrogen with Photoionization Controlled-Loss Spectroscopy," Optics Letters 11,419 (1986).

[11] J.T. Salmon and N.M. Laurendeau, "Absolute Concentration Measus sments of Atomic Hydrogen in Subatmospheric Premixed $\mathrm{H}_{2} / \mathrm{O}_{2} / \mathrm{N}_{2}$ Flat Flames with Photoionization Controlled-Loss Spectroscopy," Applied Optics 26, 2881 (1987).

[12] D.L. Peterson, F.E. Lytle and N.M. Laurendeau, "Determination of Flame Temperature Using the Anomalous Fluorescence of Pyrene," Optics Letters 11, 345 (1986).

[13] D.L. Peterson, F.E. Lytle and N.M. Laurendeau, "Flame Temperature Measurements Using the Anomalous Fluorescence of Pyrene," Applied Optics 27, 2768 (1988).

[14] J.T. Salmon and N.M. Laurendeau, "Concentration Measurements of Atomic Hydrogen in Subatmospheric Premixed $\mathrm{C}_{2} \mathrm{H}_{4} / \mathrm{O}_{2} / \mathrm{Ar}$ Flat Flames," Combustion and Flame 74, 221 
(1988).

[15] J.E.M. Goldsmith, "Two-Step Saturated Fluorescence Detection of Atomic Hydrogen in Flames," Optics Letrers 10, 116 (1985).

[16] J.E.M. Goldsmith, "Multiphoton-Excited Fluorescence Measurements of Atomic Hydrogen in Low-Pressure Flames," in Twenty-Second Symposium (International) on Combustion, The Combustion Institute, Pittsburgh, Pennsylvania, 1403 (1989).

[17] J.E.M. Goldsmith and N.M. Laurendeau, "Single-Laser Two-Step Fluorescence Detection of Atomic Hydrogen in Flames," Optics Letters 15, 576 (1990).

[18] J.T. Salmon and N.M. Laurendeau, "Relative Fluorescence-Quenching Measurements of Atomic Hydrogen in Subatmospheric $\mathrm{H}_{2} / \mathrm{O}_{2} / \mathrm{N}_{2}$ Flames with Photoionization ControlledLoss Spectroscopy," Journal of Quantitative Spectroscopy and Radiative Transfer 43, 155 (1990).

[19] R.P. Lucht, N.M. Laurendeau and D.W. Sweeney, "Temperature Measurement by Two Line Laser-Saturated OH Fluorescence in Flames," Applied Optics 21, 3729 (1982).

[20] N.M. Laurendeau, "Temperature Measurements by Light-Scattering Methods," Progess in Energy and Combustion Science 14, 147 (1988).

[21] M-S. Chou, A.M. Dean and D. Stern, "Laser-Induced Fluorescence and Absorption Measurements of $\mathrm{NO}$ in $\mathrm{NH}_{3} / \mathrm{O}_{2}$ and $\mathrm{CH}_{4} / \mathrm{A}$ ir flarnes," J.Chem. Phys. 78, 5962 (1983).

[22] L.G. Dodge, M.B. Colket and M.F. Zabielski, Nitric Oxide Measurement Study: Optical Calibration, DOT-FAA Rpt. FA77WA-4801 (1979).

[23] R. Engleman, Jr., P.E. Rouse, H.M. Peek and V.D. Baiamonte, Beta and Gamma Systems of Nitric Oxide, Los Alamos Scientific Laboratory Report LA.4364 (1970).

[24] L.G. Piper and L.M. Cowles, "Einstein Coefficients and Transition Moment Variation for the NO $\left(A^{2} \Sigma^{+}-X^{2} \Pi\right)$ Transition," J. Chem. Phy's. 85, 2419 (1986)

[25] M.C. Drake, J.W. Ratcliffe, R.J. Blint, C.D. Carter and N.M. Laurendeau, "Measurements and Modeling of Flamefront Nitric Oxide Formation and Superequilibrium Radical Concentrations in Laminar High-Pressure Premixed Flames," Twenty-third Symposium (International) on Combustion, The Combustion Institute, Pittsburgh, Pennsylvania, in press. 

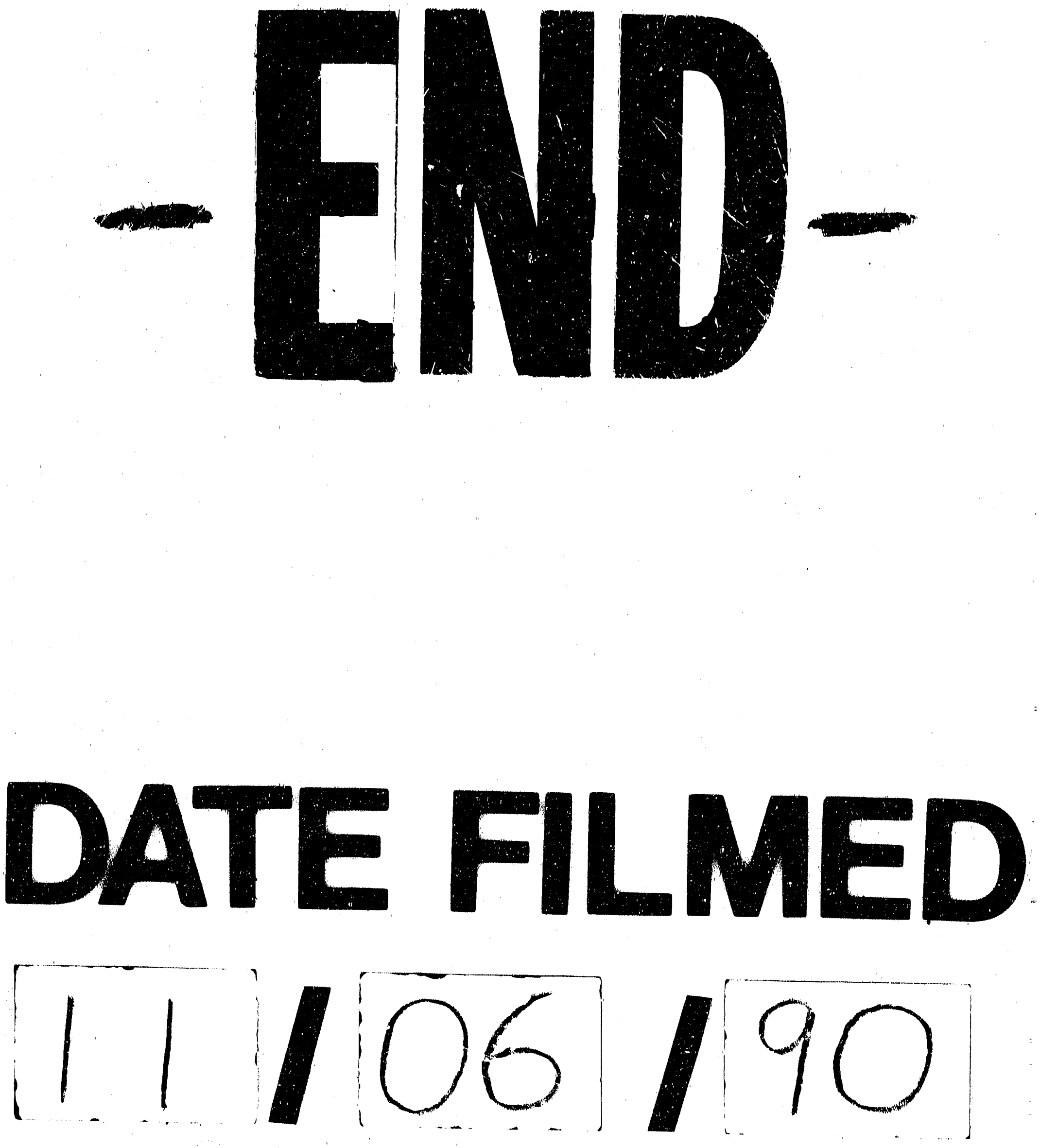
